\title{
FATE OF SUBPULMONARY HOMOGRAFT CONDUITS: DETERMINANTS OF LATE HOMOGRAFT FAILURE
}

J. Stark, MD, FRCS

C. Bull, FRCP

M. Stajevic, MD

M. Jothi, MD

M. Elliott, MD, FRCS

M. de Leval, MD, FRCS
Patients and methods: Between 1971 and 1993, 656 conduits were placed in the subpulmonary position. Patients receiving heterografts or valveless conduits and patients dying within 90 days of insertion were excluded; thus 405 homograft conduits were studied. There were 293 aortic homografts, 94 pulmonary, and 18 of unknown type. The end point of conduit failure was defined by conduit replacement for whatever reason, balloon dilation of the conduit, or death of the patient with the conduit in place. The following factors were analyzed: aortic versus pulmonary homograft, antibiotic preservation versus cryopreservation, $\mathrm{ABO}$ and $\mathrm{Rh}$ compatibility, type of material used for conduit extension, age at operation, size of the conduit, diagnosis, and reoperations. Conduit number ( 1 to 405$)$ in the series was included in the multivariable model. Results: First conduits and conduits inserted earlier in the series appeared to last longer than second and subsequent conduits and those inserted later in the series $(\boldsymbol{p}=\mathbf{0 . 0 0 1}$ and $\mathbf{0 . 0 0 3}$, respectively). Overall survival of conduits at 5, 10, and 15 years was $84 \%$ (95\% CL, 80\% to 88\%), 58\% (95\% CL, $50 \%$ to $66 \%$ ), and $31 \%(95 \% \mathrm{CL}, 19 \%$ to $43 \%)$. Corresponding figures for the first conduits were $88 \%(95 \%$ CL, 84\% to 92\%), 65\% (95\% CL, 56\% to 73\%), and $34 \%(95 \% \mathrm{CL}, 20 \%$ to $47 \%)$. The longest surviving homograft conduit in our series lasted 22.7 years. Regarded univariately, reoperation (redo worse), order number (recent worse), type of conduit (pulmonary worse than aortic), preservation (cryopreserved worse than antibiotic preserved), and age at operation (older patients worse) were statistically significant. However, in multivariable analysis, including all the above in the model, only reoperation and order number had significant predictive power. When patient survival was considered, patients operated on more recently survived longer despite the fact that their conduits were being replaced earlier. Overall, survival of patients at 5 and 15 years was 95\% (95\% CL, 93\% to 98\%) and 85\% (95\% CL, 77\% to 92\%), respectively. Conclusions: Pulmonary and aortic homografts, both cryopreserved and preserved in nutrient antibiotic solution, give similar results. All conduits will probably have to be replaced during the lifetime of the patient. In view of the worse performance of replacement conduits, techniques of repair that avoid the use of conduits should be further explored. Despite gradual deterioration of homograft conduits, they remain an important tool in the correction of many complex lesions with excellent 15-year patient survival. (J Thorac Cardiovasc Surg 1998;115:506-16)
From the Great Ormond Street Hospital for Children NHS Trust, London, United Kingdom.

Read at the Seventy-seventh Annual Meeting of The American Association for Thoracic Surgery, Washington, D.C., May 4-7, 1997.

Received for publication May 12, 1997; revisions requested Sept. 15, 1997; revisions received Nov. 3, 1997; accepted for publication Nov. 6, 1997.

Address for reprints: J. Stark, MD, FRCS, Consultant Cardiothoracic Surgeon, Great Ormond Street Hospital for Children, London WC1N 3JH, United Kingdom.

Copyright (C) 1998 by Mosby, Inc.

$0022-5223 / 98 \$ 5.00+0 \quad \mathbf{1 2 / 6 / 8 7 5 3 1}$
Extracardiac valved conduits between the subpul- monary ventricle and the pulmonary artery have been used in the repair of many complex congenital heart defects since $1966 . .^{1-3}$ After the pioneering work of Ross and Somerville ${ }^{1}$ with antibiotic-preserved homografts, preservation with irradiation was widely used in the United States. This was associated with early calcification and stenosis and widespread abandonment of homografts. Dacron conduits containing porcine heterografts ${ }^{4}$ became available commercially in various sizes and for many 


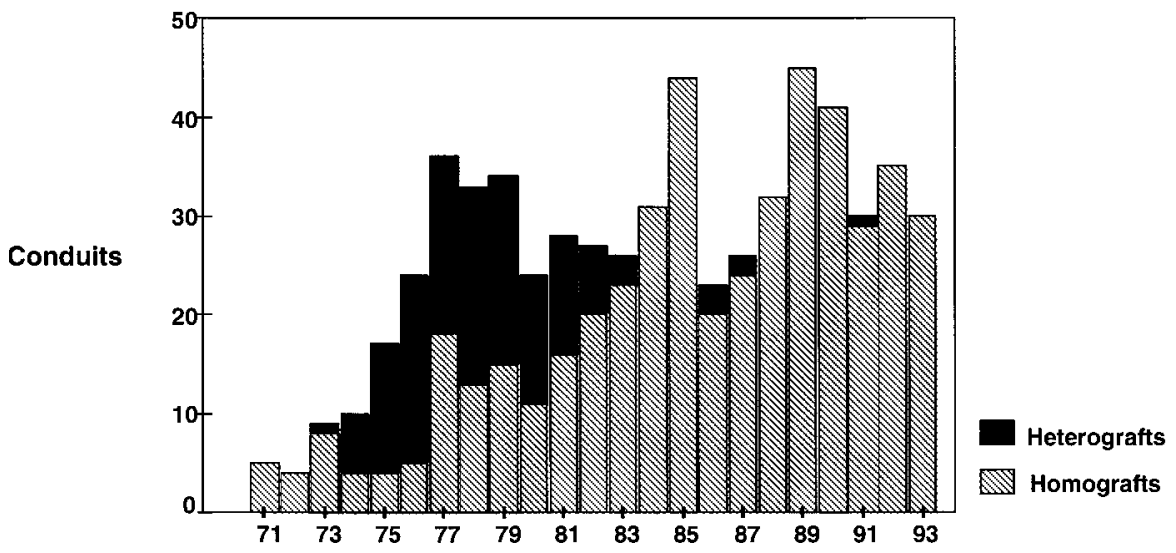

Fig. 1. Homograft and heterograft conduits used in the repair of complex congenital heart defects between 1971 to 1993 in our department.

became the conduit of choice. However, formation of neointimal peel inside Dacron conduits, ${ }^{5}$ as well as early degeneration of porcine valves in children, caused further disappointment. Preparation of homografts with cryopreservation ${ }^{6}$ and, more recently, the introduction of pulmonary homografts have provoked resurgence of their use.

This article is a retrospective analysis of the long-term results of a large series of homograft conduits inserted in the subpulmonary position, with particular emphasis on the determinants of their longevity.

\section{Patients and methods}

Between 1971 and 1993, 656 conduits were placed between the subpulmonary ventricle and the pulmonary artery (Fig. 1). Patients receiving heterografts or valveless conduits and those dying within 90 days of the operation were excluded from this study. Thus 405 homograft conduits were evaluated: 293 aortic, 94 pulmonary, and 18 of unknown type. The most common diagnostic groups are shown on Table I. There were 73 conduit replacements.

Surgical technique of homograft insertion has changed over the years. At the beginning, large homografts were used, even in infants. Smaller conduits were used during recent years to decrease the dead space. In older children we always tried to accommodate a homograft that was larger than the expected size of the pulmonary valve ring for the child's age and body surface area. The anterior cusp of the mitral valve of the homograft was used for right ventricular outflow tract reconstruction. In later years a patch (pericardium, Dacron, polytetrafluoroethylene, ${ }^{*}$ or homograft) was used to reconstruct the outflow from the right ventricle. Any stenoses at the bifurcation or at the site of a ductus or a shunt were repaired at the time of conduit insertion.

*Gore-Tex graft, registered trade mark of W. L. Gore \& Associates, Inc., Elkton, Md.
Table I. Diagnoses of patients who received homograft conduits in the subpulmonary position (Great Ormond Street Hospital, 1971 to 1993)

\begin{tabular}{lr}
\hline & No. \\
\hline TGA + VSD + LVOTO & 108 \\
Pulmonary atresia + VSD & 90 \\
Truncus arteriosus & 78 \\
Fallot's tetralogy & 53 \\
Atrioventricular discordance & 31 \\
Absent pulmonary valve + VSD & 16 \\
Other & 29 \\
Total & 405 \\
\hline
\end{tabular}

$T G A$, Transposition of the great arteries; VSD, ventricular septal defect; LVOTO, left ventricular outflow tract reconstruction.

Homografts were obtained either at routine autopsies in clean but nonsterile conditions or from multiorgan donors under operating theater conditions. Most were processed at the laboratories of the National Heart Hospital. At the beginning of the series, homografts were preserved in nutrient antibiotic solution and stored at $4^{\circ} \mathrm{C}$. The composition of the antibiotic solution changed over the years. Cryopreserved homografts ${ }^{7}$ became available in 1989 and both techniques of homograft preservation have been used since. Preference was given to homografts from younger donors and homograft stored for less than 3 weeks. ${ }^{8}$ No attempt at $\mathrm{ABO}$ or $\mathrm{Rh}$ matching was made. Pulmonary homografts became available in the late 1980s. The choice between aortic and pulmonary homografts was based on availability and the surgeon's preference and was not protocol driven or randomized.

Although we have objective information about how some aspects of management changed over the years (such as homograft type, preservation, prevalence of reoperations, and age at operation), other aspects such as indications for conduit replacement are more subtle. Recognizing that these more subtle trends in practice might also influence conduit survival in our patients, we 


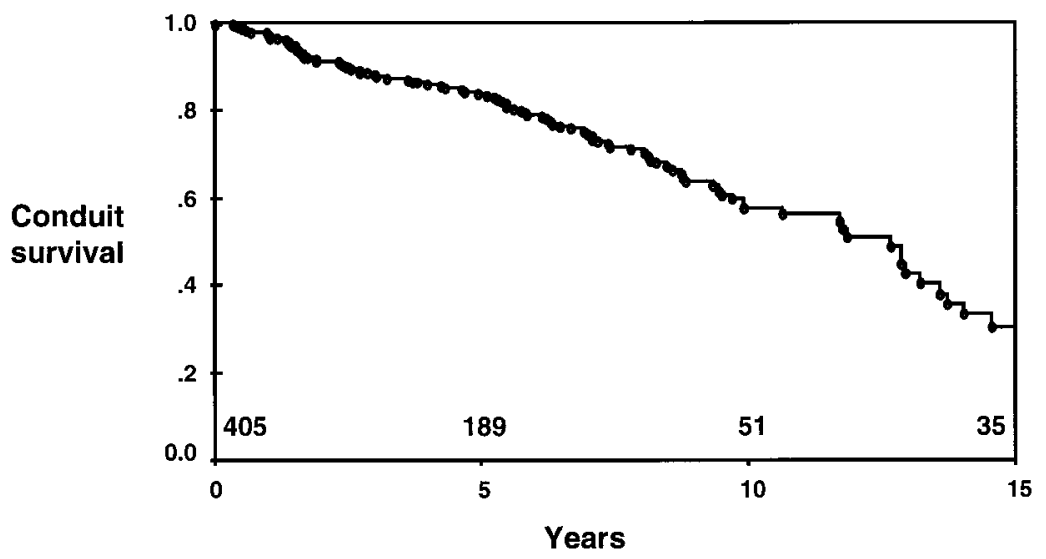

Fig. 2. Survival of homograft conduits at 5, 10, and 15 years. Numbers on this and subsequent figures show number of patients at risk.

have used the concept of "order number" in our analysis." The first conduit in 1971 was allocated number 1 and the last in the series was number 405.

Follow-up was in the first quarter of 1994, with information from our own pediatric cardiology clinics or from the referring physicians being used. In cases in which follow-up was incomplete, no assumptions were made about the patients' status beyond their last contact with our hospital. The following data were collected for analysis: diagnosis, age at operation and at last visit, reintervention or death, conduit type (aortic or pulmonary), size, mode of preservation (antibiotic preservation or cryopreservation), $\mathrm{ABO}$ and $\mathrm{Rh}$ compatibility between donor and recipient, and the material used for conduit extension (pericardium, polytetrafluoroethylene, Dacron, or "other"). In cases in which a conduit was replaced, the number of conduits (including heterografts and valveless tubes) previously used in that patient were noted. Retrospectively, it was not possible to identify the exact mechanism of conduit failure. Thus conduit replacement for conduit valve stenosis, stenosis at a proximal or distal anastomosis, stenosis of the conduit itself, endocarditis, aneurysm or pseudoaneurysm of the conduit, and compression of the conduit by sternum were all included as conduit failures.

Statistical methods. The end points for analyses of conduit survival were conduit replacement for any reason, reintervention on that conduit, or death of the patient with that conduit in place. Survival curves for the homograft conduits and for subsets of the whole group (e.g., contrasting aortic and pulmonary homografts) and for patient survival were prepared by means of Kaplan-Meier methods. ${ }^{10}$ Survival figures are quoted with $95 \%$ confidence limits (CL). Univariable and multivariable analysis of risk factors for conduit survival was performed by means of a Cox proportional hazards method ${ }^{11}$ and the same outcome end points; factors entering the final model were chosen by means of statistical and clinical criteria.

\section{Results}

Conduit survival. Follow-up ranged from 3 months to 22.8 years (mean 5.4 years). Mean age at operation was 6.8 years (range 2 days to 28 years). Of the group, $15 \%$ were infants and $15 \%$ were older than 12.5 years. The earliest conduit replacement was at 9 months, and our longest lasting conduit has been in place for 22.8 years. There were 60 first reoperations, 11 second, 1 third, and 1 fourth-time conduit replacement, 13 balloon dilatations, and 15 late deaths unassociated with reoperation with the conduit in place. Actuarial survival of all homograft conduits is shown in Fig. 2. Freedom from conduit replacement at 5, 10, and 15 years was $84 \%(95 \%$ CL, $80 \%$ to $88 \%$ ), $58 \%$ (95\% CL, $50 \%$ to $66 \%$ ), and $31 \%$ (95\% CL, $19 \%$ to $43 \%$ ), respectively.

Univariable analysis. Looked at first in isolation, the factors that were considered possibly relevant to longevity are listed in Table II. These were conduit replacement (favoring first operations over reoperations, Fig. 3), order number (favoring conduits earlier in the series), age at operation (favoring young age at operation, Fig. 4), aortic versus pulmonary (favoring aortic, Fig. 5), and preservation technique (favoring antibiotic preservation over cryopreservation, Fig. 6). There was little separation of longevity according to the diagnosis or choice of conduit extension. Conduit size (Fig. 7), ABO compatibility (Fig. 8), and Rh compatibility seemed irrelevant to conduit longevity.

Multivariable analysis. The two most powerful predictors of conduit survival related to the observed decrease in longevity of second compared with first conduits and to recent order number. The latter effect was not accounted for by the increasing prevalence of reoperations over time. When reoperations and order number were taken into account in a multivariable analysis, the apparent disadvan- 


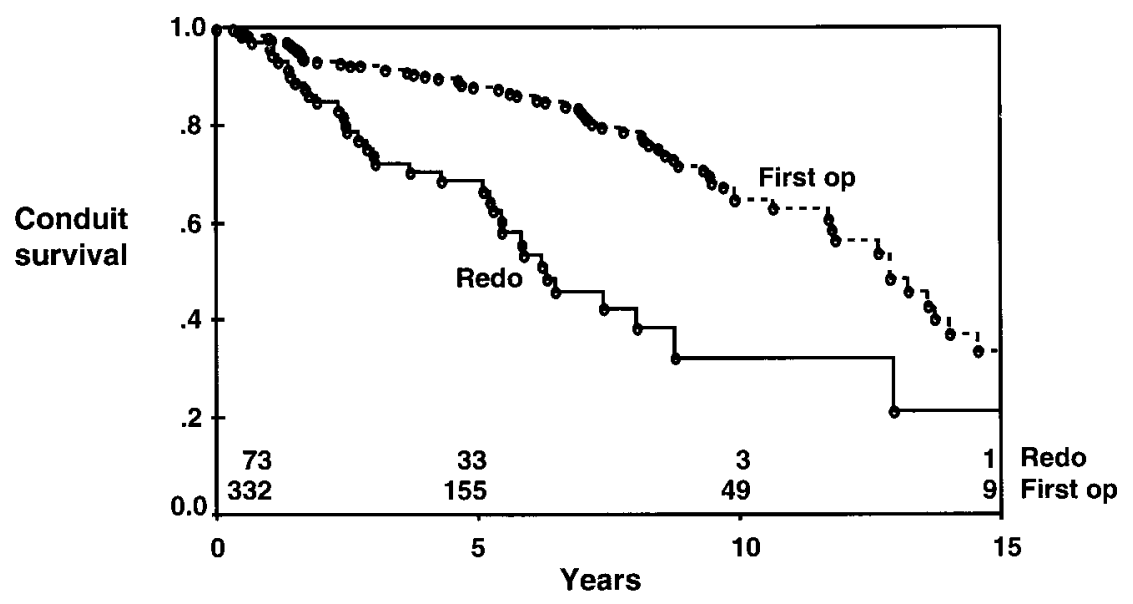

Fig. 3. Survival of first conduits compared with survival of replacement conduits.

Table II. Univariate and multivariable analysis of risk factors for conduit failure

\begin{tabular}{|c|c|c|c|c|c|c|c|}
\hline \multicolumn{4}{|c|}{ Univariate } & \multicolumn{4}{|c|}{ Multivariate } \\
\hline Factor & Worse & $B$ & $p$ & Factor & Worse & $B$ & $p$ \\
\hline First conduit or redo & Redo & 1.08 & 0.00001 & First conduit or redo & Redo & 1.06 & 0.00001 \\
\hline Order number & Recent & 0.0065 & 0.00001 & Order number & Redo & 0.005 & 0.003 \\
\hline Age at operation (yr) & Older & 0.65 & 0.002 & Age at operation & & 0.01 & 0.64 \\
\hline Aortic or pulmonary & Pulmonary & 0.46 & 0.04 & Aortic or pulmonary & & 0.57 & 0.06 \\
\hline Preservation & Cryopreservation & 0.05 & 0.05 & Preservation & & -0.19 & 0.55 \\
\hline Conduit size (mm) & & 0.03 & 0.35 & Conduit size $(\mathrm{mm})$ & & 0.002 & 0.97 \\
\hline $\mathrm{ABO}$ match & & 0.21 & 0.45 & & & & \\
\hline $\mathrm{Rh}$ match & & -0.05 & 0.90 & & & & \\
\hline $\begin{array}{l}\text { Conduit extension } \\
\text { (pericardium vs "else") }\end{array}$ & & -0.13 & 0.08 & & & & \\
\hline $\begin{array}{l}\text { Diagnosis (truncus vs } \\
\text { "else") }\end{array}$ & & -0.31 & 0.24 & & & & \\
\hline
\end{tabular}

$B$, Regression coefficient (the log of the odds on death for a given patient compared with the baseline).

tage of older age at operation, pulmonary over aortic homografts, and cryopreservation over antibiotic preservation lost significance. All these factors were confounded with recent order number.

In the final model (Table II), which attempts to evaluate independently each possible risk factor, only two remain significant: order number and reoperation (use of second and subsequent conduit).

Patient survival. Overall subsequent survival, regardless of intervening reoperations, of all 405 patients receiving homograft conduits in the era 1971 to 1993 who survived at least 90 days from their first conduit insertion is shown in Fig. 9. Patients receiving their first conduit before and after 1980 are contrasted. When an "order number" was applied to this data set according to the date of the patient's first operation, recent order number was associated with increased patient survival $(p=0.0009)$.

\section{Discussion}

The aim of this study was to investigate the determinants of longevity of homograft conduits. In particular, we wanted to know if there were factors intrinsic to the conduit itself that would influence how long it would last in a patient. These factors included type of homograft (aortic versus pulmonary), mode of preservation (antibiotic versus cryopreservation), $\mathrm{ABO}$ and $\mathrm{Rh}$ compatibility with the recipient, and conduit size. To investigate these possibilities in an observational study, we also had to understand the influence of a variety of other factors extrinsic to the conduit itself; these include the underlying diagnosis of the patients and whether the conduit was the first, second, third, or fourth conduit for that patient. Over the years practice regarding conduit management has changed in many respects; in cases in which we have objective data about how 


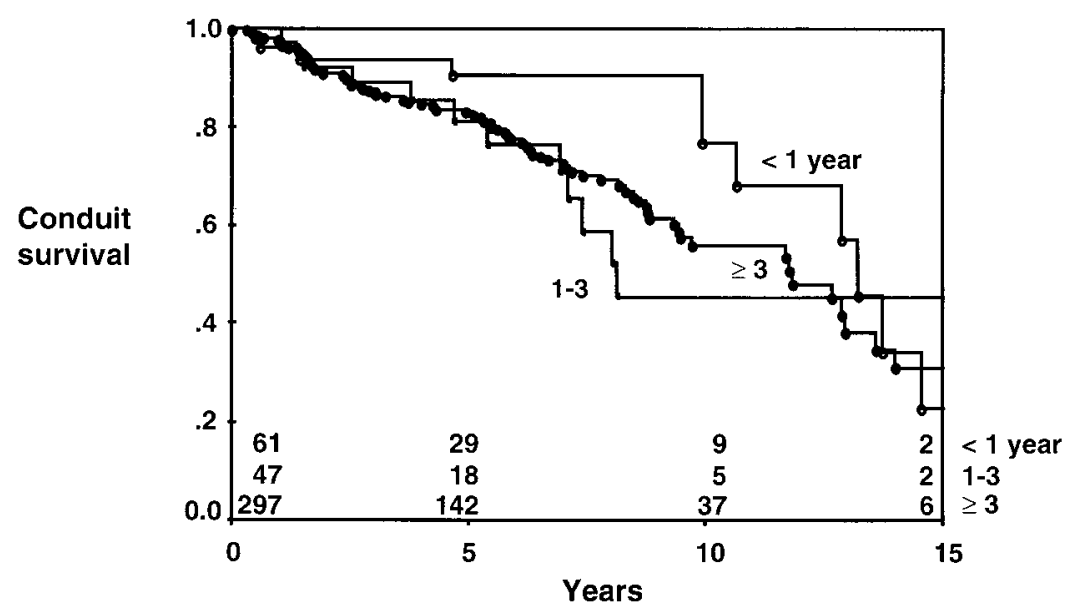

Fig. 4. Survival of homograft conduits in three age groups $(<1,1-3$, and $>3$ years).

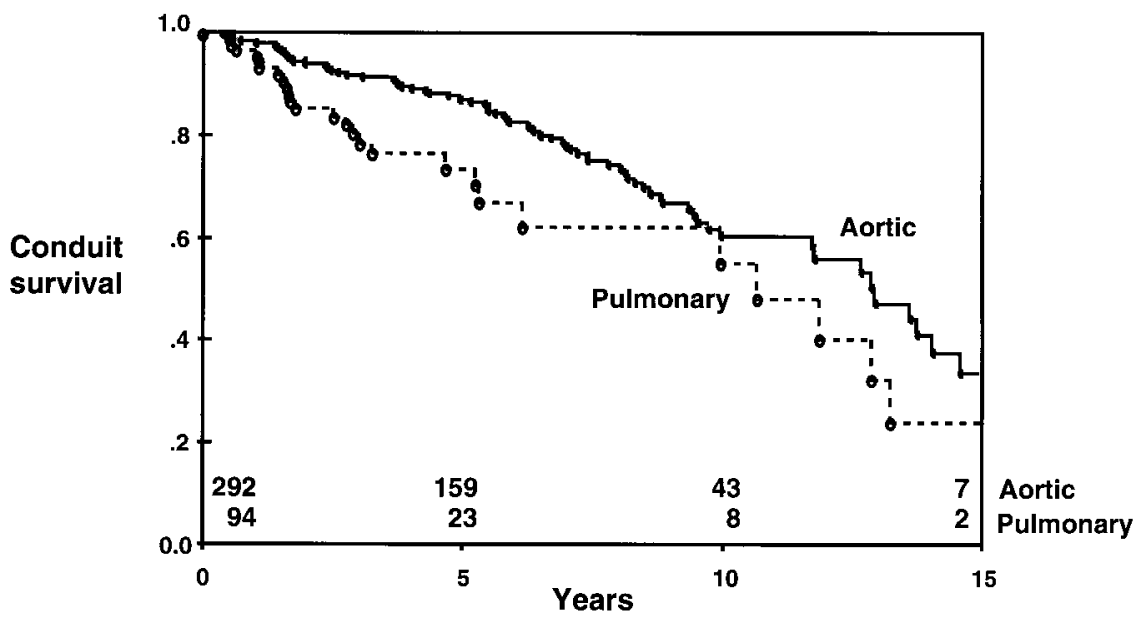

Fig. 5. Survival of aortic homografts compared with survival of pulmonary homografts.

these changed over time, we can allow for their interaction in the analysis. Others changes in "fashions" about conduit management (such as indications for elective conduit replacement) are much less easy to handle rigorously because the changes in practice have been gradual and not protocol driven.

No mechanism exists for directly measuring conduit deterioration; conduit survival in the patient was used as a proxy measurement. Unfortunately, conduit survival in a patient is determined by factors other than deterioration of the conduit. Conduit replacement, for whatever reason, other intervention on the conduit (e.g., a balloon dilatation), or the death of the patient with that conduit in place was considered as conduit failure. These together will probably overestimate the prevalence of conduit deterioration, but there is no reason to expect that choice of these end points will produce a spurious bias in the analysis of possible risk factors. Also, because our main interest was in the determinants of the conduit deterioration beyond the immediate postoperative period, only data from conduits still in place 90 days after insertion were included; conduit deterioration rarely accounts for early postoperative death or need for conduit revision. Most other articles include the early postoperative hazard, which almost certainly has different determinants.

Replaced conduits. Our finding that the second and subsequent conduits had shorter freedom from failure (see Fig. 3) than the original conduits was surprising and rather worrisome. We suspect that technical details may play an important role. Be- 


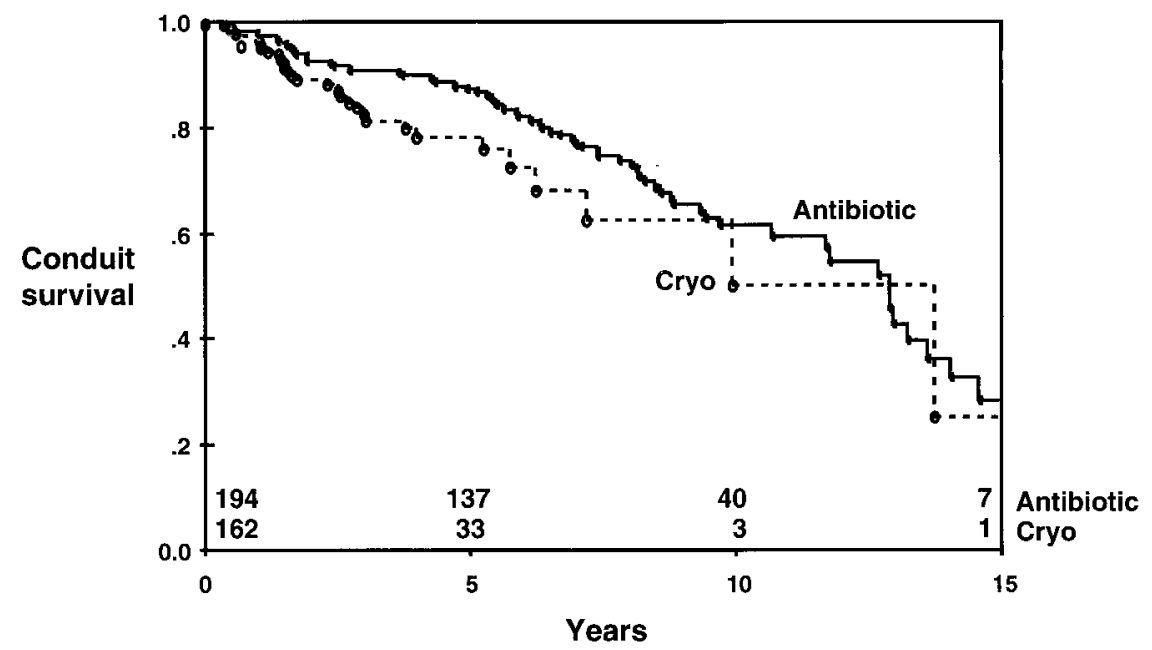

Fig. 6. Survival of homografts preserved in nutrient/antibiotic solution compared with survival of cryopreserved homografts.

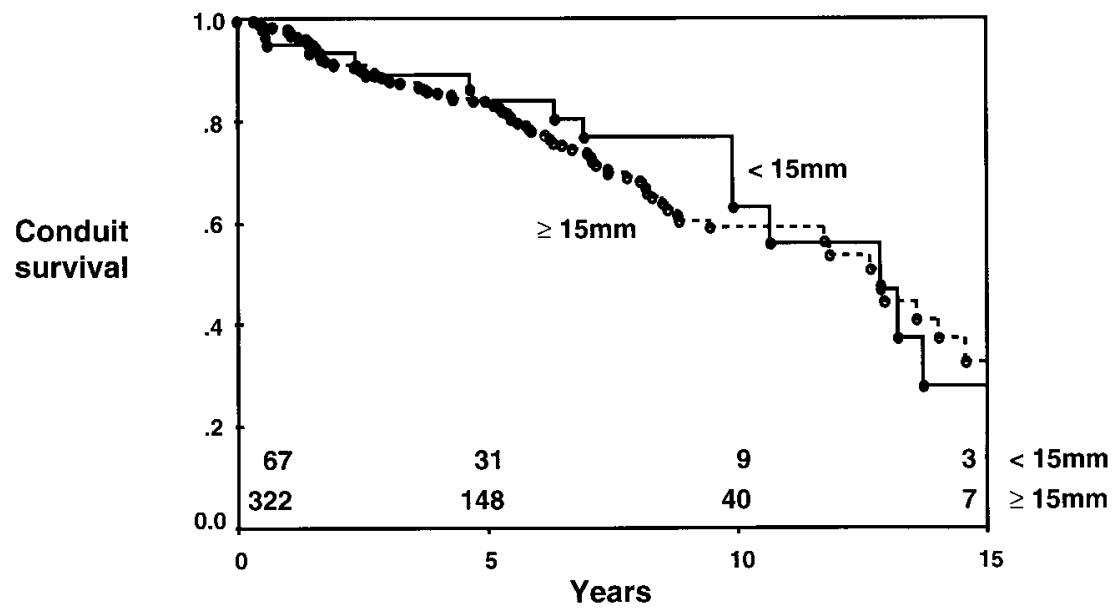

Fig. 7. Survival of small $(<15 \mathrm{~mm})$ and large $(>15 \mathrm{~mm})$ homograft conduits.

cause of adhesions and calcification of adjacent tissues, it may be more difficult to obtain an ideal fit and flow characteristics at reoperation. In addition, there may be a variety of other subtle technical details that have yet to be identified. Another argument supporting the importance of operative technique is information published by Razzouk and associates $^{12}$ from Toronto. In their series, the best results were achieved with pulmonary valve insertion rather than with use of the conduit. Five-year survival after pulmonary valve insertion was $89 \% \pm$ $5 \%$ irrespective of whether a homograft or heterograft valve was used. This contrasted with 5 -year survival of $46 \% \pm 1.3 \%$ of homograft conduits.
Because of these findings about replacement conduits, we believe that techniques of repair avoiding conduits ${ }^{13-15}$ should be further explored.

Order number. The second factor relevant to conduit longevity in our series was the "order number." Surprisingly, it was not the recent but the early conduits that lasted longer. This was not accounted for by the increasing prevalence of reoperation with time. Looking at the long-term survival of patients as opposed to survival of the conduits, the patients' survival in recent years was better than in earlier years. For this not to be a paradox, we suggest that the explanation lies in our increasing readiness to reoperate early on inadequate conduits. Experience 


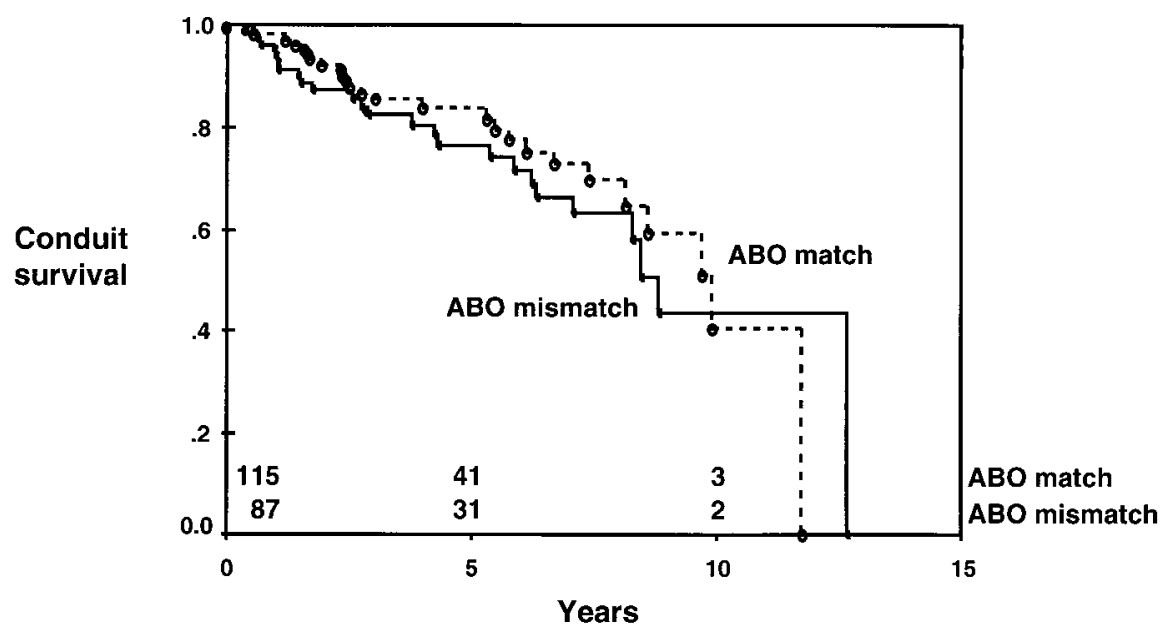

Fig. 8. Survival of $A B O$ matched and mismatched homografts.

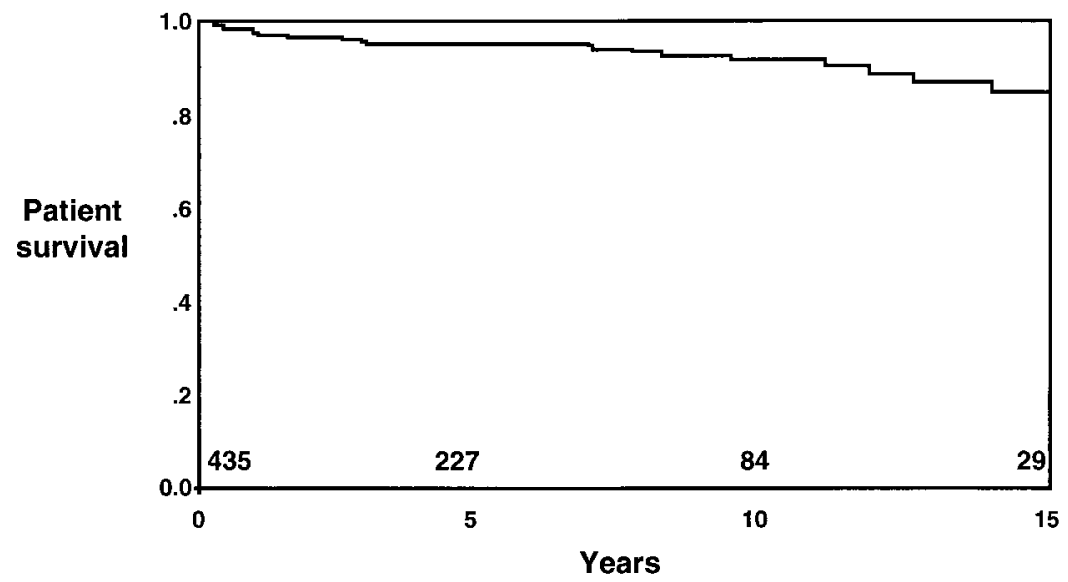

Fig. 9. Long-term survival of patients (who survived 90 days after conduit insertion).

of others ${ }^{16,17}$ and our own increasing experience confirmed that conduits can be replaced with low risk and that the function of the ventricle may determine the patient's outcome after conduit replacement. As a consequence, conduit replacement is now probably undertaken earlier than in the past. Thus, in our analysis, shorter survival of the conduits in recent years may be appropriate as the pattern is associated with improved survival of the patients over time.

Aortic versus pulmonary conduits. When pulmonary homografts were introduced as right ventricular outflow tract conduits, it was hoped that they would perform better than the aortic homografts. Freedom from reoperation was better in pulmonary compared with aortic homografts in some series. ${ }^{18-20}$
Schorn and coworkers ${ }^{20}$ found freedom from calcification to be $100 \%$ at 1 year for pulmonary homografts and $33 \%$ for aortic homografts. Five-, 10-, and 15-year survival of aortic homografts in our series was $87 \%$ (95\% CL, 83\% to $91 \%$ ), $60 \%$ (95\% CL, $52 \%$ to $69 \%$ ), and $34 \%$ (95\% CL, $19 \%$ to $48 \%$ ) compared with $73 \%$ (95\% CL, $62 \%$ to $85 \%$ ), $55 \%$ (95\% CL, $36 \%$ to $74 \%$ ), and $24 \%$ (95\% CL, $3 \%$ to $46 \%$ ) for pulmonary homografts (see Fig. 5). In multivariable analysis this difference was not strictly significant $(p=0.06)$; in our series, use of pulmonary homografts was confounded with "recent order number" and with reoperation. Freedom from reoperation was similar for aortic and pulmonary homografts in the experience of Cleveland, ${ }^{21}$ Hawkins, ${ }^{22}$ and their colleagues. 
Methods of preservation. Cryopreservation improved longevity of aortic homograft valves placed in the aortic position. ${ }^{6,23}$ Cryopreservation of homograft conduits did not produce similar results. Cleveland and coworkers, ${ }^{21}$ reporting results from Toronto, concluded that performance of cryopreserved homografts in the pulmonary position was disappointing. Homografts preserved in antibiotic/ nutrient solution performed well in the experience of Kay and Ross ${ }^{24}$ and Tam and colleagues. ${ }^{25}$ In our series, cryopreserved homografts appeared to perform somewhat worse (see Fig. 6), but the difference could be accounted for by association with recent patient number and-according to our hypothesiswith earlier reintervention on deteriorating homografts in recent years. Thus we believe that the use of both types of preservation is justified. Cryopreservation has the additional advantage of longer storage time compared with antibiotic/nutrient solutions.

Age factor for conduit failure. Contrary to results of other studies, ${ }^{12,18,20,24,26}$ young age was not a significant risk factor for conduit survival in our series. Five-year freedom from reoperation was $43 \%$ in Clarke and Bishop's series ${ }^{27}$ and $48 \%$ in Schorn's data. ${ }^{20}$ Age under 4 years was a risk factor in the Mayo Clinic experience. ${ }^{18}$ These data contrast with our 5- and 10-year freedom from conduit failure for the conduits that were still in place 90 days after the original operation. It was $91 \%(95 \% \mathrm{CL}, 82 \%$ to $98 \%$ ) and $77 \%$ (95\% CL, $58 \%$ to $96 \%$ ) for infants (see Fig. 4), $81 \%$ (95\% CL, $67 \%$ to $95 \%$ ) and $46 \%$ (95\% CL, $23 \%$ to $69 \%$ ) for 1 - to 3 -year-old patients, and $83 \%(95 \% \mathrm{CL}, 78 \%$ to $88 \%)$ and $50 \%(95 \%$ CL, $47 \%$ to $65 \%$ ) for children aged over 3 years at the time of conduit replacement. In multivariable analysis (see Table II) we did not identify age as a risk factor $(p>0.2)$. Unlike most other studies, our analysis excludes early postoperative attrition.

Size of the homograft. Several series suggest that small conduits constitute a risk factor for early conduit failure. ${ }^{19,21,25}$ Surprisingly, our follow-up of conduits still in place 90 days after the original operation shows no influence of conduit size on conduit longevity, either when examined as a single variable or when age at operation ("size for age") is taken into account.

Immunologic response. Immunologic response as a factor in homograft deterioration was suspected by Clarke and Bishop. ${ }^{27}$ Schorn and coworkers ${ }^{20}$ also suspected that immunologic reaction may be a major factor in homograft deterioration, and they recommend use of immunosuppression. Baskett and coworkers ${ }^{26}$ demonstrated that a short interval from retrieval to cryopreservation was a risk factor for homograft failure. The authors speculated that the short interval may produce "viable" homografts that could be more antigenic. In our series, $\mathrm{ABO}$ or $\mathrm{Rh}$ compatibility between donor and recipient appeared to confer no advantage.

\section{Conclusion}

We have found no factor intrinsic to the conduit that determines its longevity in the patient. However, second and subsequent conduits appeared to fare significantly worse than the first conduit. Conduits implanted more recently are electively removed earlier, but patient survival is better than in our earlier experience.

\section{REFERENCES}

1. Ross DN, Somerville J. Correction of pulmonary atresia with a homograft aortic valve. Lancet 1964;2:1446-7.

2. McGoon DC, Rastelli GC, Ongley PA. An operation for the correction of truncus arteriosus. JAMA 1968;205:69-73.

3. Rastelli GC, McGoon DC, Wallace RB. Anatomic correction of transposition of the great arteries with ventricular septal defect and subpulmonary stenosis. J Thorac Cardiovasc Surg 1969;58:545-52

4. Bowman RO, Hancock WD, Malm JR. A valve containing Dacron prosthesis: its use in restoring pulmonary artery-right ventricular continuity. Arch Surg 1973;107:724-8.

5. Agarwal KC, Edwards WD, Feldt RM, Danielson GK, Puga FJ, McGoon DC. Clinicopathological correlates of obstructed right-sided porcine-valved extracardiac conduits. J Thorac Cardiovasc Surg 1981;81:591-601.

6. O'Brien MF, Stafford EG, Gardner MAH, Pohlner PG, McGiffin DC. A comparison of aortic valve replacement with viable cryopreserved and fresh allograft valves, with a note on chromosomal studies. J Thorac Cardiovasc Surg 1987;94:81223.

7. McNally R, Barwick R, Smith-Morse B, Rhodes P. Actuarial analysis of a uniform and reliable preservation method for viable heart valve allografts. Ann Thorac Surg 1989;48:583-4.

8. Bull C, Macartney FJ, Horvath P, Almeida R, Merrill W, Douglas J, et al. Evaluation of long-term results of homograft and heterograft valves in extracardiac conduits. J Thorac Cardiovasc Surg 1987;94:12-9.

9. Altman DG, Royston JP. The hidden effect of time. Stat Med 1988;7:629-37.

10. Kaplan EL, Meier P. Nonparametric estimation from incomplete observations. J Am Stat Assoc 1958;53:457-81.

11. Cox DR. Regression models and life tables. J R Stat Soc B 1972;34:187-220.

12. Razzouk AJ, Williams WG, Cleveland DC, Coles JG, Rebeyka IM, Trusler GA, et al. Surgical connections from ventricle to pulmonary artery: comparison of four types of valved implants. Circulation 1992;86(Suppl):II154-8.

13. Lecompte Y, Zannini L, Hazan E, Jarreau MM, Bex JP, Tu $\mathrm{TV}$, et al. Anatomic correction of transposition of the great 
arteries: new technique without the use of a prosthetic conduit. J Thorac Cardiovasc Surg 1981;82:629-31.

14. Danielson GK, Downing TP, Schaff HV, Puga FJ, Di Donato RM, Ritter DG. Replacement of obstructed extracardiac conduits with autogenous tissue reconstructions. J Thorac Cardiovasc Surg 1987;93:555-9.

15. Cerfolio RJ, Danielson GK, Warnes CA, Puga FJ, Schaff $\mathrm{HV}$, Anderson BJ, et al. Results of an autologous tissue reconstruction for replacement of obstructed extracardiac conduits. J Thorac Cardiovasc Surg 1995:110:1359-68.

16. Sano S, Karl TR, Mee RB. Extracardiac valved conduits in the pulmonary circuit. Ann Thorac Surg 1991;52:285-90.

17. Jonas RA, Freed MD, Mayer JE Jr, Castaneda AR. Longterm follow-up of patients with synthetic right heart conduits. Circulation 1985;72:(Suppl):II77-83.

18. Bando K, Danielson GK, Schaff HV, Mair DD, Julsrud PR, Puga FJ. Outcome of pulmonary and aortic homografts for right ventricular outflow tract reconstruction. J Thorac Cardiovasc Surg 1995;109:509-18.

19. Heinemann MK, Hanley FL, Fenton KN, Jonas RA, Mayer JE, Castaneda AR. Fate of small homograft conduits after early repair of truncus arteriosus. Ann Thorac Surg 1993;55: 1409-12.

20. Schorn K, Yankah AC, Alexi-Meskhishvili VA, Weng Y, Lange PE, Hetzer R. Risk factors for early degeneration of allografts in pulmonary circulation. Eur J Cardiothorac Surg 1997;11:62-9.

21. Cleveland DC, Williams WG, Razzouk AJ, Trusler GA, Rebeyka IM, Duffy L, et al. Failure of cryopreserved homograft valved conduits in the pulmonary circulation. Circulation 1992;86(Suppl):II150-3.

22. Hawkins JA, Bailey WW, Dillon T, Schwartz DC. Midterm results with cryopreserved allograft valved conduits from the right ventricle to the pulmonary arteries. J Thorac Cardiovasc Surg 1992;104:910-6.

23. Kirklin JK, Smith D, Novick W, Naftel DC, Kirklin JW, Pacifico $\mathrm{AD}$, et al. Long-term function of cryopreserved aortic homografts. J Thorac Cardiovasc Surg 1993;106:15466.

24. Kay PH, Ross DN. Fifteen years' experience with the aortic homograft: the conduit of choice for right ventricular outflow tract reconstruction. Ann Thorac Surg 1985;40:360-4.

25. Tam RK, Tolan MJ, Zamvar VY, Slavik Z, Pickering R, Keeton BR, et al. Use of larger sized aortic homograft conduits in right ventricular outflow tract reconstruction. $\mathrm{J}$ Heart Valve Dis 1995;4:660-4.

26. Baskett RJ, Ross DB, Nanton MA, Murphy DA. Factors in the early failure of cryopreserved homograft pulmonary valves in children: Preserved immunogenicity? J Thorac Cardiovasc Surg 1996;112:1170-9.

27. Clarke DR, Bishop DA. Allograft degeneration in infant pulmonary valve allograft recipients. Eur J Cardiothorac Surg 1993;7:365-70.

\section{Discussion}

Dr. F. Mark Lupinetti (Seattle, Wash.). This large and carefully analyzed experience offers many interesting insights. I was surprised by at least five of the authors' findings: specifically, redo allografts did worse, more recent allografts did worse, pulmonary grafts did worse than aortic grafts, grafts in older patients did worse, and larger grafts did no better than smaller grafts. That all of these findings were counterintuitive emphasizes the need for careful statistical methods and should encourage us to apply similarly meticulous analyses to our own results.

I have two questions for Mr. Stark regarding the factors found to be significant by multivariate analysis. First, would you speculate on at least one possible explanation for the findings that more recent patients had poor graft survival? Over the more than two decades of this experience, presumably the patient population had become younger and sicker and had more challenging anatomy. Is it fair to assume that the more complicated nature of the patients and their operations contributed to the shorter graft survival in more recent times?

Second, I would like you to comment on the importance of immunologic factors in the accelerated degeneration of second and subsequent grafts. Several studies, most notably that of Mark O'Brien, have shown that recipient immunosensitization occurs early, affects nearly all allograft recipients, and persists for a long time after implantation. Although I share your bias that technical factors are the most important determinants of graft success, don't your findings also support the hypothesis that immune factors are important as well and that second allograft failure can be interpreted as a second-set immune response?

Dr. Guillermo O. Kreutzer (Buenos Aires, Argentina). Our experience with homografts is similar to yours, and I agree that the greater number of reoperations, the greater the risk and problems for patients. All currently available homografts present problems during the long term. Because of this, in 1983 we started our experience with our own untreated pericardial valve conduit developed by my colleague, Dr. Andy Schliecter. Our work was published in July 1996 in the Annals of Thoracic Surgery. Previous requirements are mandatory: no previous pericardial adhesions or high pulmonary vascular resistances. Fifty-one patients were followed up for 1 to 10 years, mean 50 months. In our opinion, it is the only available conduit whose diameter tends to increase, as happened in 27 of the 51 patients. Patients with an implanted conduit with a diameter more than $15 \mathrm{~mm}$ do not need to be reoperated on. Freedom from reoperation in our series is $95.4 \%$ at 8 years for patients operated on after January 1986. Consequently, at present it is our conduit of choice until tissue engineering produces valved conduits with the potential for growth. Even more, its use is advisable for economic reasons because reduction of medical costs is mandatory even in developed countries.

Dr. David B. Ross (Halifax, Nova Scotia, Canada). Mr. Stark, you postulate in the abstract that flow dynamics may explain the accelerated rate of failure of second and subsequent homografts. An alternative explanation, of course, is that immunologic sensitization may be the cause, as discussed by Dr. Lupinetti.

In addition to Mark O'Brien's findings, we have reported an increased risk of failure of homografts on the right side with very well preserved and thus more antigenic grafts.

Corneal grafts are similar to homografts in that they are implanted without immunosuppression and are thought to be immunologically privileged. My colleagues in our tissue-typing laboratory report evidence of increased long- 
term survival with HLA-matched corneal grafts. Have you considered performing this HLA matching prospectively as we are doing at Halifax?

Dr. Christopher Caldarone (Toronto, Ontario, Canada). At the Hospital for Sick Children in Toronto we are concluding an analysis of approximately 905 operations in which a pulmonary valve or a valved conduit was placed between the right ventricle and the pulmonary artery. Of these, there are approximately 400 homografts and approximately $40 \%$ of these were aortic homografts.

By univariate analysis we did not detect a difference between homograft types. Because we did identify age as a univariate predictor of valve survival, we performed a slightly different analysis in that we stratified the group of patients on the basis of age at operation into four separate quartiles, the youngest patients in the first quartile, up to the oldest patients in the fourth quartile. Doing multivariable analysis on each quartile, we found different important predictors of valve survival at different ages at operation.

Specifically, in the first quartile, valve type and size seemed to be important predictors of valve survival. This was in an age group ranging from neonates up to $1 \frac{1}{2}$ years. In the second and fourth quartiles, valve size was the only predictor we could detect for conduit survival.

In light of these findings, we would ask whether you considered an age-based stratified analysis to identify important factors at different ages at operation. Second, we are concerned about the use of death as an end point for conduit failure. If you removed death as an end point in your analysis, did you find different results?

Dr. Richard A. Hopkins (Providence, R.I.). I have a comment and a question. I think this is a very important paper. One always likes to see articles that challenge currently accepted myths, especially when they support one's own beliefs.

Mr. Stark, were the homografts cryopreserved in-house by you or by others? Did they come from a long distance or were they from London donors?

Mr. Stark. Dr. Lupinetti, thank you very much for your comments. We were equally surprised by some of our findings because we did not expect them. During the last few years, I personally preferred pulmonary homografts because in small babies I find the suturing much easier in pulmonary as opposed to aortic homografts. We were surprised that pulmonary homografts did not perform as well as aortic ones. However, in multivariate analysis there was no difference in longevity between pulmonary and aortic homografts.

With regard to the performance of redo conduits, there are possible explanations. When there are adhesions and calcifications, it may be more difficult to obtain an ideal fit for the conduit. If we do not obtain ideal flow patterns, this may contribute to early deterioration of the homograft.

The explanation for the fact that recent patients had poor homograft survival is only speculative. As we became more confident in replacing the homografts, it is possible that in recent years we have explanted homograft conduits earlier than previously in the series. In the absence of clear-cut protocols for conduit replacement, this is certainly a possibility. When we looked at the survival of patients, as opposed to survival of the conduits, we found that patients in the more recent series are surviving better than in our earlier experience. It may therefore be that earlier replacement of the conduits is an appropriate strategy because it is followed by improved rather than worse patient survival.

With regard to your question about the importance of immunologic response, I think one has to differentiate between the use of homografts as aortic valve substitutes compared with homografts used in conduits in the subpulmonary position. All the data from the literature suggest that homografts behave differently in these two positions. Harvesting of homografts in our series was almost entirely from cadavers; therefore, we cannot claim that our homografts were "viable." This, and the fact that $\mathrm{ABO}$ and $\mathrm{Rh}$ compatibility did not influence the survival of our homograft conduits, would suggest that immunologic factors did not play a role.

Dr. Ross, I am aware of the work that was done in Halifax, in particular your finding that a very short interval between harvesting and preservation was a risk factor. As I have already mentioned, we did not think that our homografts were viable because they were almost always harvested from cadavers. If the homografts are harvested at the time of heart transplantation, and the time between harvest and preservation is very short, it is possible that immunologic factors play a role. This was also suggested by the group from Deutsches Herzzentrum in Berlin. I believe the data from our study cannot add anything to the question of immunologic response except to state again that $\mathrm{ABO}$ and $\mathrm{Rh}$ matching did not play a role.

Dr. Kreutzer, I would include your technique of using patients' pericardium in what I called alternative techniques to standard homografts. Your results are outstanding, although the follow-up is only 5 to 7 years. We will have to wait another 10 to 15 years, but I believe you have devised a good approach to this difficult problem. The economic aspect of your operation is also important.

Dr. Caldarone, the way you analyzed your patients in four separate quartiles is an interesting approach. It is interesting that the survival of conduits is very similar in our series and in your Toronto series, but the risk factors for conduit replacement are different. I have already discussed this with Dr. Williams. Perhaps we should pool our results and analyze them as one group. With regard to your second question, we did not remove death as an end point in our analysis. Reoperation or death of the patient with a conduit in place were the end points of our analysis. We removed only an early death (less than 3 months after the operation) so as not to confuse patient survival with conduit survival.

I believe that the Toronto series also supports our idea that technical aspects may be important. One of the earlier publications by Razzouk showed considerable difference if the patient received a homograft conduit compared with pulmonary valve implantation. Irrespective of what type of pulmonary valve was implanted, the 5-year survival was $89 \%$ whereas the homograft conduit survival was only $49 \%$. The importance of technical aspects was also emphasized by data from Boston Children's Hospital (Heinemann). This group carefully measured gradients after the insertion of the conduit. Patients who had a 
mean gradient between the right ventricle and pulmonary artery of $1.7 \mathrm{~mm} \mathrm{Hg}$ had much better long-term survival of conduits than did the group of patients in whom the gradient was $7 \mathrm{~mm} \mathrm{Hg}$. In our series, our operating reports did not have such detailed information.

Dr. Hopkins, most of our homografts come from the laboratory that was originally established by Donald Ross at the National Heart Hospital, which is now located at the Royal Brompton Hospital. The laboratory preserved the homografts in antibiotics and nutrient solution, and cryopreservation was added later as an alternative method of preservation. The donors came from southern England, and they were generally cadavers. In addition, when we could not obtain the desired homograft size from this laboratory, some homografts were supplied from Southampton, Sheffield, Liverpool, and Harefield.

\section{ON THE MOVE?}

Don't miss a single issue of the journal! To ensure prompt service when you change your address, please photocopy and complete the form below.

Please send your change of address notification at least six weeks before your move to ensure continued service. We regret we cannot guarantee replacement of issues missed due to late notification.

\section{JOURNAL TITLE:}

Fill in the title of the journal here.

\section{OLD ADDRESS:}

Affix the address label from a recent issue of the journal here.

\section{NEW ADDRESS:}

Clearly print your new address here.

Name

Address

City/State/ZIP
COPY AND MAIL THIS FORM TO:

Periodical Subscription Services

Mosby, Inc.

11830 Westline Industrial Dr.

St. Louis, MO 63146-3318
OR FAX TO:

314-432-1158

N/ Mosby
OR PHONE:

1-800-453-4351

Outside the U.S., call

314-453-4351 